\title{
Do Males and Females Differ in Terms of Their Knowledge, Attitude, Perception (KAP) Regarding Halal Pharmaceuticals?
}

\author{
Saleha Sadeeqa, Azmi Sarriff \\ Discipline of Clinical Pharmacy, School of Pharmaceutical Science, \\ Universiti Sains Malaysia, Malaysia
}

\begin{tabular}{l} 
Article Info \\
\hline Article history: \\
Received April 12, 2014 \\
Revised Aug 02, 2014 \\
Accepted Aug 23, 2014
\end{tabular}

\section{Keyword:}

Attitude

Halal

Knowledge

Perception

Pharmaceuticals

\begin{abstract}
There is an increasing awareness amongst Muslim consumers to avoid all items containing non-Halal ingredients including medications. Male and female are different both biologically and psychologically; it therefore, needed for a study to compare KAP of males and females regarding Halal pharmaceuticals. This was a cross-sectional study using a structured, selfadministered questionnaire to compare the knowledge, attitude \& perception regarding Halal pharmaceuticals, among males and females in Penang state of Malaysia. Results revealed that there is no significant difference in the knowledge, attitude and perception of males and females. This is concluded that males and females are equally aware and have same attitude and perception regarding Halal pharmaceuticals. P value of .05 or less was taken as statistically significant.
\end{abstract}

Copyright @ 2014 Institute of Advanced Engineering and Science. All rights reserved.

\section{Corresponding Author:}

Saleha Sadeeqa, Discipline of Clinical Pharmacy, School of Pharmaceutical Science, Universiti Sains Malaysia. Email: salehasadeeqa@gmail.com

\section{INTRODUCTION}

Halal is an Arabic word which means "lawful", "permissible" under Islamic law [1]-[3]. The opposite of Halal is "Haram" which means " unlawful", " prohibited", "forbidden" [4],[5]. Halal and Haram are universal terms that apply to all facets of life. However, this study will adapt these terms to refer only to pharmaceutical products that are deemed permissible for consumption of Muslims.

Halal is a well known word in the entire Muslim world. However as the Muslim population is expanding in other continents, this word has come to be used so commonly in the day to day life that even the non-islamic world has become cognizant of this terminology. This has resulted in Halal signs, at shops and food products, in America and Europe, catering for the religious beliefs and needs of the Muslim consumers.

Medicines play a pivotal role in the process of human development as their rational use can decrease the morbidity and mortality as well as improve the quality of life [6]. A drug/medicine is composed of a combination of active ingredients, and excipients. These substances are obtained from a variety of sources animals, plants or synthetic origin [7],[8]. In case of animal source, it may be porcine, dead animal or blood. All these are Haram/forbidden for Muslims as mentioned in the Holy Quran [9]-[11]. It is evident that, not only, consuming Halal food but also consuming Halal medication is important because it forms a major part and behaviour of being a good practicing Muslim.

It is a firm belief of all Muslims that Allah is our creator and He is the best judge of what is right for us to consume and in what shape it should be done. However it is pertinent to mention that all old religions of the world like Hinduism, Judaism and Christianity also command certain religious restrictions and bindings on their followers in the consumption of foods and drinks [12],[13]. They may use other terminologies to define these restrictions but the main sentiment is the same. Therefore it would be pertinent to look into 
various items of human consumption, including medicines, and their variants, to determine admissibility according to individual beliefs.

As majority of Malaysian population is Muslim [14], there are many government and non government organizations which are playing an active role to ensure provision of Halal foods and Pharmaceuticals to Muslim consumers in Malaysia. In Muslim society, generally females are responsible for educating their families. Males and females are different in all major traits of their character and thinking process. Moreover their strong and weak points differ drastically [15]. Many studies have been done to compare knowledge, attitude and perception of males and females in different fields, but to the best of our knowledge no study has been done so far to compare the knowledge, attitude and perception of males and females regarding Halal pharmaceuticals. Therefore the main objective of this study is to compare levels of knowledge, attitude and perception among male and female consumers. To achieve this objective, an extensive study was undertaken to reach various cross sections of the society, targeting all variants of the consumers.

\section{RESEARCH METHOD}

\section{Ethical consideration}

Ethical approval to conduct this study was taken from "Joint Ethics Committee of School of Pharmaceutical Sciences, USM and Hospital Lam Wah Ee on Clinical Studies" and Ministry of Health Malaysia.

\section{Study design and site}

A cross-sectional study design was adopted by using structured, self-administered questionnaires with a representative sample of general public, in the Penang state of Malaysia from September 2012 to November 2012. Participants were recruited from different shopping malls, bus stations, food courts and markets of Penang state.

\section{Questionnaire design}

After extensive literature review, a self administered questionnaire was designed to conduct this study. The questionnaire was validated by the panel of experts which was composed of eight senior academic researchers and was updated according to their recommendations. A pilot study was conducted to evaluate the reliablity of the updated questionnaire on 46 consumers (which is $10 \%$ of the total study sample [16]. Cronbach's alpha was applied to test validity and internal consistency of the questionnaire [17]. Final modifications were based upon the results of pilot study.The final questionnaire consisted of four parts. The first part of the questionnaire was on respondent's demographic informations including age, gender, race, religion, nationality occupation, level of education, suffering from any chronic disease and frequency of purchasing medicines from pharmacy. Second part had 9 statements to evaluate the knowledge of respondents towards Halal pharmaceuticals. Third part consists of 7 statements for perception evaluation of the respondents towards Halal pharmaceuticals and final part had 7 statements about the attitude of respondents about Halal pharmaceuticals. For knowledge statements respondents were asked to choose "Yes" or "No" options. Correct answer (yes) was scored one (1) while incorrect answer (no) was scored zero. A five point Likert scale was used for perception and attitude statements (strongly agree $=5$, agree $=4$, neutral $=3$, disagree $=2$ and strongly disagree $=1$ ). Hence the minimum and maximum score for knowledge, attitude and perception can be 0 to 9,1 to 35,1 to 35 respectively. Total KAP score can be 79 .

Questionnaire was initially developed in English language and, was translated into Malaysian national language, Malay due to language fluency and barrier to English language. The translation was done by language experts from School of Languages, Literacy and Translations Universiti Sains Malaysia”.The Malay version of translated questionnaire was back translated into English to ensure for any changes in the meaning of original questionnaire by the language experts other than the translators.

\section{Selection criteria of respondents}

Any Muslim having age 18 years and above, able to read and understand Malay language and willing to participate in the study was recruited as 'study participant'.

\section{Distribution and Collection of questionnaires}

Trained data collectors were recruited for data collection under the direct supervision of principle investigator. All questionnaires were labeled with date, time and location of the respondent. A verbal consent 
was taken before distributing questionnaires from each respondent and they were assured for confidentiality of their personal information. No incentives were offered to any of the respondent [18].

Data analysis

After collecting questionnaires from data collectors, data was entered in SPSS version 18. After data cleaning, normality of data was checked by Kolmogorov-Smirnov test. Descriptive statistics (mean, standard deviation, frequency, percentage, median, inter quartile range) was applied to summarize the data. As data was not normally distributed, so non-parametric tests were applied. The Mann-Whitney U Test was applied to test for difference between male's and female's knowledge, attitude.and perception [19]. $\mathrm{P} \geq .05$ was taken as statistically significant.

\section{RESULTS AND DISCUSSION}

Respondents demographics

A total of 458 respondents participated in the study. A total of 237(51.7\%) respondents were male and $221(48.3 \%)$ were females. Age range was between 18-65 years with a mean of 32.28 years and Standard Deviation of \pm 10.998 .

\section{Comparing knowledge regarding Halal pharmaceuticals between male and female respondents}

Comparison between male and female knowledge regarding Halal pharmaceuticals is depicted in Table 1 and Table 4. Results revealed that there is no significance difference in the level of knowledge (regarding Halal pharmaceuticals) of males $(\mathrm{Md}=6, \mathrm{n}=236)$ and females $(\mathrm{Md}=6, \mathrm{n}=221), \mathrm{U}=25753.000$, $\mathrm{z}=-.237, \mathrm{p}=.813$.

\section{Comparing attitude regarding Halal pharmaceuticals between male and female respondents}

Comparison between male and female attitude regarding Halal pharmaceuticals is depicted in Table 2 and Table 4. Results revealed that there is no significance difference in the level of attitude (regarding Halal pharmaceuticals) of males $(\mathrm{Md}=25, \mathrm{n}=236)$ and females $(\mathrm{Md}=25, \mathrm{n}=221), \mathrm{U}=25034.500$, $\mathrm{z}=-.743, \mathrm{p}=.458$.

\section{Comparing perception regarding Halal pharmaceuticals between male and female respondents}

Comparison between male and female knowledge regarding Halal pharmaceuticals is depicted in Table 3 and Table 4. Results revealed that there is no significance difference in the level of Perception (regarding Halal pharmaceuticals) of males $(\mathrm{Md}=32, \mathrm{n}=237$ ) and females $(\mathrm{Md}=32, \mathrm{n}=220), \mathrm{U}=$ $25523.500, \mathrm{z}=-.391, \mathrm{p}=.696$. 
Table 1. Comparison of Knowledge between males and females

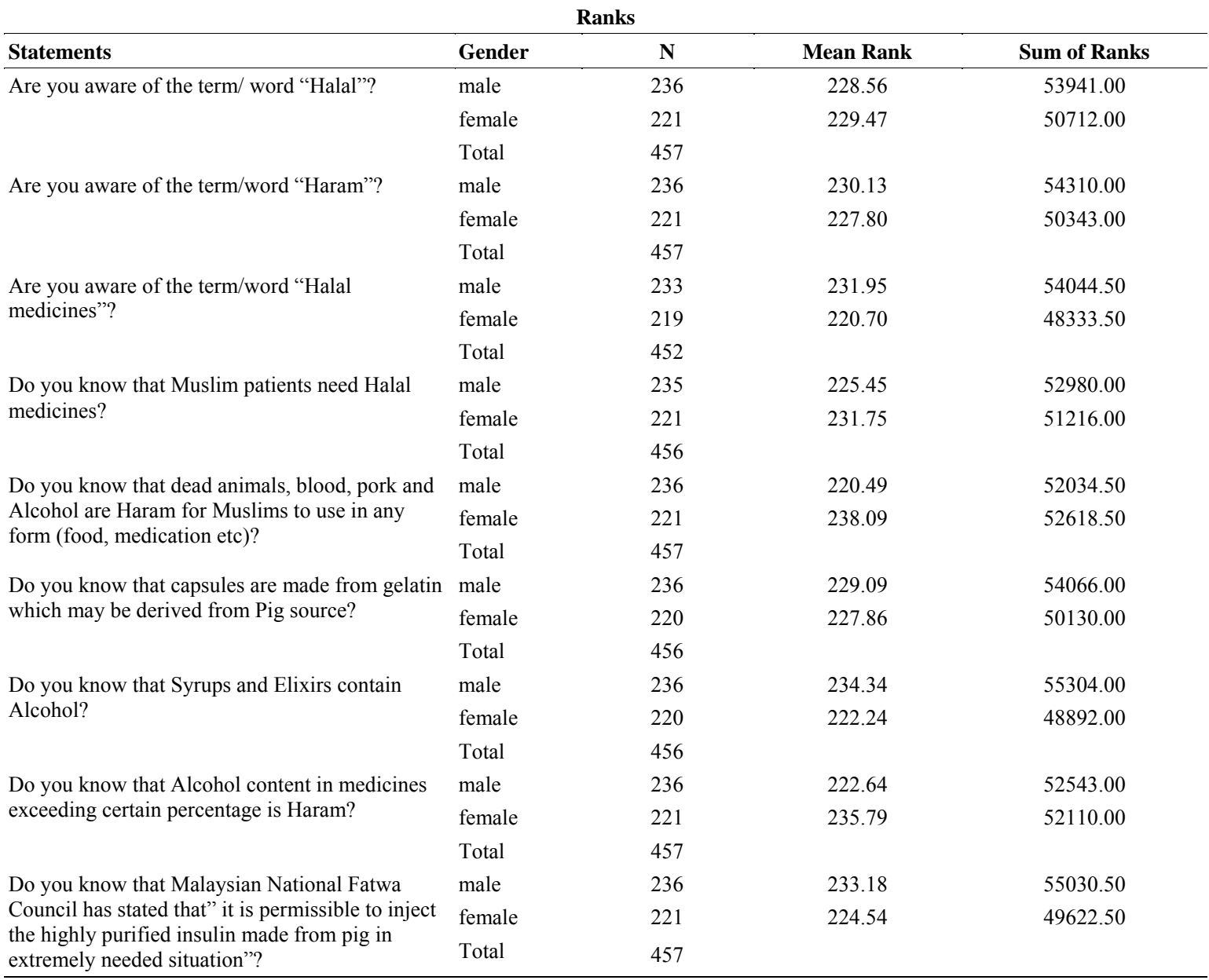

Table 2. Comparison of attitude between males and females

\begin{tabular}{|c|c|c|c|c|}
\hline \multicolumn{5}{|c|}{ Ranks } \\
\hline Statements & Gender & $\mathbf{N}$ & Mean Rank & Sum of Ranks \\
\hline \multirow[t]{3}{*}{ I prefer to purchase Halal medicines. } & male & 236 & 230.56 & 54412.00 \\
\hline & female & 221 & 227.33 & 50241.00 \\
\hline & Total & 457 & & \\
\hline \multirow{3}{*}{$\begin{array}{l}\text { I talk to the doctor about the sources of ingredients of } \\
\text { medicine before accepting the prescription. }\end{array}$} & male & 236 & 236.44 & 55800.50 \\
\hline & female & 221 & 221.05 & 48852.50 \\
\hline & Total & 457 & & \\
\hline \multirow{3}{*}{$\begin{array}{l}\text { I talk to the Pharmacist about the sources of ingredients } \\
\text { before accepting the medicines. }\end{array}$} & male & 236 & 228.80 & 53997.50 \\
\hline & female & 221 & 229.21 & 50655.50 \\
\hline & Total & 457 & & \\
\hline \multirow{3}{*}{$\begin{array}{l}\text { I am comfortable if pharmacist changes the prescription } \\
\text { because of Halal/Haram issue. }\end{array}$} & male & 236 & 233.86 & 55190.00 \\
\hline & female & 221 & 223.81 & 49463.00 \\
\hline & Total & 457 & & \\
\hline \multirow[t]{3}{*}{ I used to get information about the sources of my medicine. } & male & 236 & 225.55 & 53230.00 \\
\hline & female & 219 & 230.64 & 50510.00 \\
\hline & Total & 455 & & \\
\hline \multirow[t]{3}{*}{ I used to take Halal medicine without considering cost issue. } & male & 236 & 214.77 & 50685.00 \\
\hline & female & 221 & 244.20 & 53968.00 \\
\hline & Total & 457 & & \\
\hline \multirow[t]{3}{*}{ I like to see 'Halal logo 'on my medicine. } & male & 236 & 218.83 & 51645.00 \\
\hline & female & 221 & 239.86 & 53008.00 \\
\hline & Total & 457 & & \\
\hline
\end{tabular}


Table 3. Comparison of perception between males and females

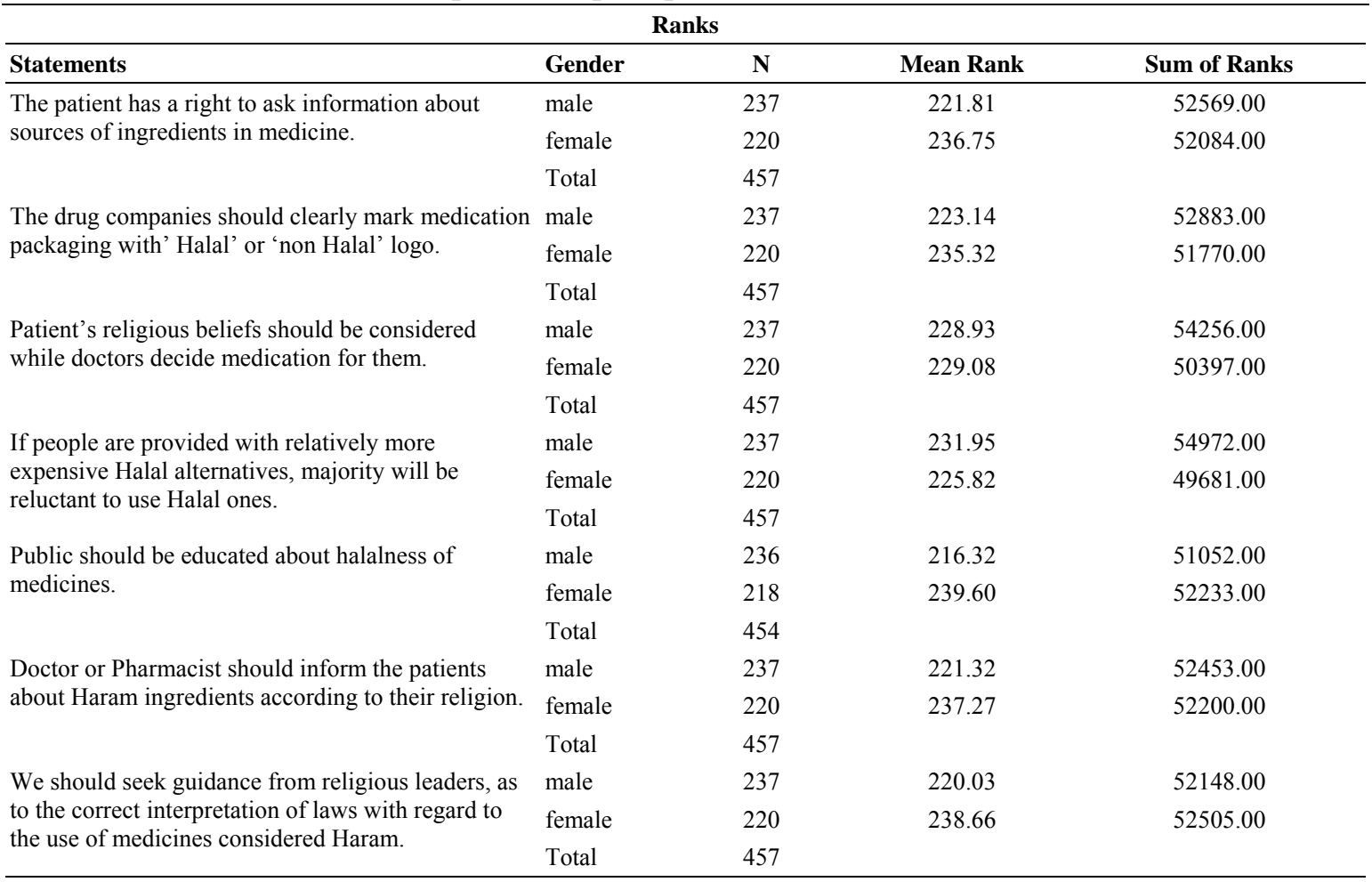

Table 4. Comparison of KAP scores between males and females

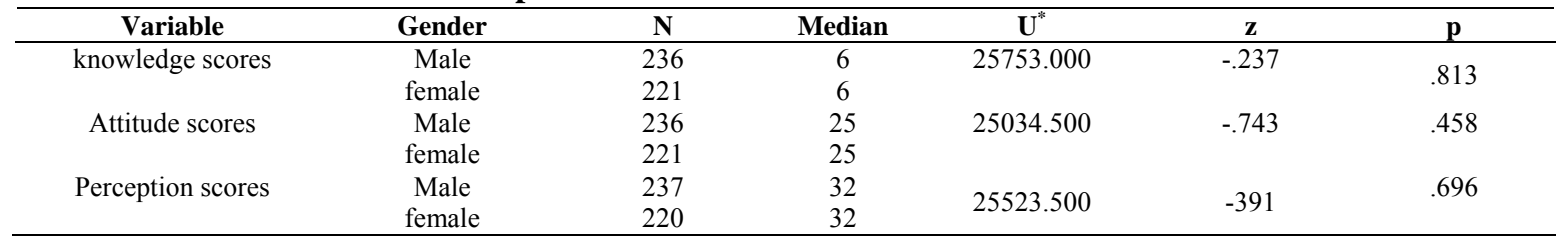

* Mann-Whitney U , Note: $\mathrm{N}$ =observed values; missing values are excluded

The study was aimed to evaluate and compare the knowledge, attitude and perception of males and females in Penang state of Malaysia. A total of 458 respondents participated in the survey. Intensive literature review found no such study which is conducted to compare the knowledge, attitude and perception of males and females on the issues surrounding Halal pharmaceuticals among general public. Men and women, in spite of a few variations, may not really be that different from each other.Though many studies have been done to compare attitude and perception of males and females in other fields.In almost all societies it seems to be a certain cultural belief that males and females are different [20]. Some of the studies point out differences in the biological functioning of the two genders, such as the recent report from the University of Indiana proposed that while women use both sides of their brain while listening, men use only the left side of theirs in similar situations (LA Times), or the newer article in the Neurobiology of Learning and Memory, claims that male and female process their emotional memories in opposite sides of the amygdale region of the brain [21]. Other studies focus more on finding different patterns of behavior among males and females.These studies generally argue that there are different patterns of leadership behavior [22]-[24]. This study tried to explore the knowledge of males and females about Halal pharmaceuticals. Study findings showed that both categories had a good knowledge and positive attitude and perception towards issues surrounding Halal pharmaceuticals. Their level of awareness, their attitude and perception are almost the same.

\section{CONCLUSION}

It can be concluded that there is no significance difference in the knowledge, attitude and perception of males and females. They are equally aware and have same attitude and perception regarding Halal pharmaceuticals.

Do Males and Females Differ in Terms of Their Kap Regarding Halal Pharmaceuticals (Saleha Sadeeqa) 


\section{ACKNOWLEDGEMENTS}

We thank all the respondents who participated in the study.We would also like to thank all students who helped in data collection.

\section{Conflict of Interest}

Authors have disclosed no conflict of Interest

\section{Key points}

- Study evaluated knowledge, attitude and perception of males and females regarding Halal pharmaceuticals.

- Study compared the knowledge, attitude and perception of males and females regarding Halal harmaceuticals.

- Study explored the idea of Halal pharmaceuticals among males and females.

\section{REFERENCES}

[1] Nasaruddin, R. R., MEL, M., Fuad, F., Jaswir, I. \& ABD.Hamid, H., "The Importance of a Standardized Islamic Manufacturing for Food and Pharmaceutical Productions", 2nd International Conference on professional Ethics and Education in Engineering, 2011

[2] Peng, K., \& Karim, R. H. A., "Halal Pharmaceuticals", Regulatory Focus, 2012. http://www.raps.org/focusonline/news/news-article-view/article/2505/halalpharmaceuticals.aspx.

[3] Husain, R., Ghani, I. A., Mohammad, A. F., \& Mehad, S., "Current Practices among Halal Cosmetics Manufacturers in Malaysia", Journal of Statistical Modeling and Analytic, vol/issue: 3(1), pp. 46-51, 2012.

[4] Riaz, M.N., Chaudry, M.M., "Halal Food Production", Florida: CRC Press, Boca Raton, 2004

[5] MS 1500, "Requirements for Production of Halal Food", 2004.

[6] Cohen \&Kohler, "The morally uncomfortable global drug gap", Clin Pharmacol Ther., vol/issue: 82(5), pp. 610 614, 2007.

[7] Geraldine M., Ghalamkari, H., Beaumont, S., Powell, S., \& McGee, P., "Informed Choice In Medicine Taking", Drugs of Porcine Origin \& Clinical Alternatives Medicines Partnership, London, 2004.

[8] Hoesli, T. M., \& Smith, K. M., "Effects of Religious and Personal Beliefs on Medication Regimen Design", Orthopedics, vol/issue: 34(4), pp. 292, 2011.

[9] Al-Quran Chapter 2 verse 168, Quran Explorer. Availablefrom: http://www.quranexplorer.com/quran/

[10] Al-Quran Chapter 2 verse 173, Quran Explorer. Available from: http://www.quranexplorer.com/quran/.

[11] Al-Quran Chapter 5 verse 3, Quran Explorer. Available from: http://www.quranexplorer.com/quran/

[12] Mynors G. H. Ghalamkari, S. Beaumont, S. Powell, and P. McGee, "Informed Choice in Medicine Taking: Drugs of Porcine Origin \& Clinical Alternatives", London: Medicines Partnership, 2004.

[13] Easterbrook C. and G. Maddern, "Porcine and Bovine Surgical Products: Jewish, Muslim, and Hindu Perspectives", Archives of Surgery, vol. 143, pp. 366, 2008.

[14] Population and Housing Census, "Malaysia 2010, population distribution and basic demographic characteristic report 2010", Dept. of Statistics Malaysia.

[15] Baron-Cohen, "The Essential Difference”, Penguin Press Science, WS, United Kingdom, 2003.

[16] Bonett, D. G., "Sample Size Requirements for Testing and Estimating Coefficient Alpha", Journal of Educational and Behavioral Statistics, vol. 27, pp. 335-340, 2002.

[17] De Bourdeaudhuij, I., Klepp, K., Due, P., Rodrigo, C. P., De Almeida, M., Wind, M., Krolner, R., Sandvik, C. \& Brug, J., "Reliability and validity of a questionnaire to measure personal, social and environmental correlates of fruit and vegetable intake in 10-11-year-old children in five European countries", Public Health Nutrition-Wallingford, vol. 8, pp. 189-200, 2005.

[18] Edwards, P., Roberts, I. \& Clarke, M., "Increasing response rates to postal questionnaires:systematic review", BMJ, pp. 324, 2002.

[19] Pallant J., "SPSS Survival Manual: A Step by Step Guide to data Analysis Using SPSS", Sydney: Allen and Unwin, 2011.

[20] Mahdavi, I., "Comparing Men's and Women's Definition of success”, Journal of Behavioral Studies in Business, 2011.

[21] Cahill, Larry, Haier, R.J, White, N.S., Fallon, J., Kilpatrick, L., Lawrence, G., Potkin, S. G., and Alkire, M. T., "Sex-Related Differences in Amygdala Activity During Emotionally Influenced Memory Storage", Neurobiology of Learning and Memory, Vol/issue: 75(1), pp. 1-9, 2001.

[22] Helgesen, “The Female Advantage: Women's Way of Leadership”, New York: Doubleday, 1990

[23] Deaux K., "Sex Differences" in M.R. Roseenzweig and L. W. Porter (eds.), Annual Review Of Psychology, Vol. 26, pp. 48-82, 1985.

[24] Eagly, A.H and Johnson, B. T., "Gender and Leadership Style: A Meta-Analysis”, Psychological Bulletin, pp. 233$56,1990$. 